\title{
Lack of MMP-9 expression is a marker for poor prognosis in Dukes' B colorectal cancer
}

\author{
Selja Koskensalo ${ }^{1}$, Jaana Hagström², Nina Linder ${ }^{3}$, Mikael Lundin³ ${ }^{3}$ Timo Sorsa ${ }^{4}$, Johanna Louhimo ${ }^{1}$ \\ and Caj Haglund $d^{1,2^{*}}$
}

\begin{abstract}
Background: Matrix metalloproteinases (MMPs) play a role in cancer progression by degrading extracellular matrix and basement membranes, assisting in tumour neovascularization and in supporting immune response in cancer.

Methods: We studied the prognostic value of immunohistochemical expression of MMP-2, MMP-8, and MMP-9 in a series of 619 colorectal cancer patients using tissue microarray specimens.

Results: Of the samples, 56\% were positive for MMP-2, 78\% for MMP-8, and 60\% for MMP-9. MMP-9 associated with low WHO grade $(p<0.001)$. In univariate analysis of Dukes' B tumours, MMP-9 negativity associated with poor survival $(p=0.018)$, and MMP-9 positivity was an independent prognostic marker in multivariate analysis of these tumours $(p=0.034)$.
\end{abstract}

Conclusion: Negative MMP-9 expression can predict poor prognosis in Dukes' B colorectal tumours and may prove useful for identifying patients, who should be offered adjuvant treatment.

Keywords: MMP-2, MMP-8, MMP-9, Colorectal cancer, Prognosis, Immunohistochemistry

\section{Background}

Colorectal cancer (CRC) is the third most common malignancy in the world [1]. The most important prognostic factor in colorectal cancer is stage of disease at diagnosis. Other factors for poor prognosis are venous and lymphatic invasion, deficient healthy tissue margins at surgery, obstruction or perforation of the bowel, and poor differentiation at histology [2-5]. In addition to tumour-specific factors, also host responses, such as intra- or peritumoral inflammation and desmoplasia or reactive lymph nodes can suppress tumour spread and predict better outcome [6-8]. In cancer progression and spread, tumours must invade their surrounding tissues, basement membranes (BM), and extracellular matrix (ECM), must avoid the host's immunoresponse, and must ascertain their circulation by neovascularization. In all these phenomena, matrix metalloproteinases (MMPs) play an important role [9].

MMPs are zinc-dependent endopeptidases capable of degrading both BM and ECM proteins and extracellular

\footnotetext{
* Correspondence: caj.haglund@hus.fi

${ }^{1}$ Department of Surgery, Helsinki University Central Hospital, P.O. Box 440, 00029 HUS, Helsinki, Finland

${ }^{2}$ Department of Pathology, Haartman Institute, University of Helsinki, Helsinki FIN-00014 HY, Finland

Full list of author information is available at the end of the article
}

adhesion molecules. MMP-9, also known as gelatinase B, is able to degrade collagens IV (the main component of $\mathrm{BM}$ ) and V, gelatins, and elastin. MMP-2, also known as gelatinase $\mathrm{A}$, is able to degrade the same substrates as MMP-9, but also collagens I, VII, X, fibronectin and procollagenase-3 [9]. MMP-8, also called collagenase-2, is able to degrade collagens I, II and III [10].

In CRC, MMP-2 immunoexpression associates with advanced disease $[11,12]$, and high MMP-2 expression in cancer cells and the stroma associates with poor prognosis $[11,13]$. MMP-9 correlates with metastatic disease $[11,14,15]$ and poor prognosis [14], although conflicting findings exist [16]. MMP-8 is expressed in many cancer types $[17,18]$ and may protect against cancer spread by regulating tumour metastasis [18].

In this study, we studied the prognostic value of MMP-2, MMP-8 and MMP-9 immunoexpression in colorectal cancer.

\section{Methods}

\section{Patients}

Sample material came from 643 consecutive patients who underwent surgery for CRC at the Department of Surgery, Meilahti Hospital, Helsinki University Central Hospital, 
between 1982 and 1998. Of these, 18 patients were excluded on account of incorrect final diagnosis (9 patients) or synchronous multiple tumours (9 patients). Six cases were excluded because of insufficient archival surgical tissue specimens. Finally, 619 cases remained, 330 of them male. Tumour staging was performed according to the modified Dukes' classification [19], with 91 tumours classified as Dukes' stage A, 226 as stage B, 161 as stage C, and 145 as stage D. For patients' clinicopathological characteristics, see Table 1.

Clinical data were retrieved from patient records, and survival and cause of death data until March 2011 from the Population Register Centre of Finland, and Statistics Finland.

For MMP-9, we also stained tissue microarray (TMA) specimens from a validation series of 213 CRC patients treated between 1998-2001, 82 of them male; 31 tumours were classified as Dukes' stage A, 70 stage B, 69 stage C, and 41 stage D, with 201 of tumours being adenocarcinomas; with 7 being grade I, 161 grade II, 37 grade III, and 4 grade IV. Clinical data was retrieved, as for the main cohort, until October 2011.

\section{Tissue samples and preparation of TMA blocks}

Formalin-fixed and paraffin-embedded surgical tissue samples were collected from the archives of the Department of Pathology, University of Helsinki. Histopathologically representative regions of tumour specimens were defined and marked on H\&E slides. Three cores from each tumour block were sampled with $1.0 \mathrm{~mm}$ punchers with a manual tissue microarrayer (Tissue Arrayer 1, Beecher Instruments Inc., Silver Spring, MD, USA). Three

Table 1 Patient clinicopathological characteristics and their correlation with MMP-2, MMP-8, and MMP-9 immunoreactivity in colorectal cancer patients assessed with chi-square test

\begin{tabular}{|c|c|c|c|c|c|c|c|c|c|c|c|c|}
\hline \multirow{3}{*}{$\frac{\text { Clinicopathological }}{\text { variable }}$} & \multicolumn{4}{|c|}{ MMP-2 } & \multicolumn{4}{|c|}{ MMP-8 } & \multicolumn{4}{|c|}{ MMP-9 } \\
\hline & \multirow{2}{*}{$\begin{array}{c}\text { Patients } \\
(n=)\end{array}$} & \multicolumn{2}{|c|}{ positive } & \multirow[t]{2}{*}{$p$-value } & \multirow{2}{*}{$\begin{array}{c}\text { Patients } \\
(n=)\end{array}$} & \multicolumn{2}{|c|}{ positive } & \multirow[t]{2}{*}{$p$-value } & \multirow{2}{*}{$\begin{array}{c}\text { Patients } \\
(\mathrm{n}=)\end{array}$} & \multicolumn{2}{|c|}{ positive } & \multirow[t]{2}{*}{$p$-value } \\
\hline & & (n) & $\%$ & & & (n) & $\%$ & & & $(n)$ & $\%$ & \\
\hline Gender & & & & 0.887 & & & & 0.496 & & & & 0.574 \\
\hline Female & 272 & 153 & 56.3 & & 257 & 194 & 75.5 & & 257 & 158 & 61.5 & \\
\hline Male & 309 & 172 & 55.7 & & 301 & 235 & 78.1 & & 301 & 192 & 63.8 & \\
\hline Age & & & & 0.107 & & & & 0.343 & & & & 0.197 \\
\hline$<65$ years & 244 & 146 & 59.8 & & 228 & 183 & 80.3 & & 238 & 142 & 59.7 & \\
\hline$\geq 65$ years & 337 & 179 & 53.1 & & 320 & 246 & 76.9 & & 320 & 208 & 65.0 & \\
\hline Dukes' stage & & & & 0.317 & & & & 0.148 & & & & 0.100 \\
\hline$A$ & 87 & 44 & 50.6 & & 82 & 63 & 76.8 & & 83 & 57 & 68.7 & \\
\hline$B$ & 208 & 110 & 52.9 & & 197 & 163 & 82.7 & & 206 & 138 & 67.0 & \\
\hline C & 155 & 93 & 60.0 & & 137 & 99 & 72.3 & & 138 & 77 & 55.8 & \\
\hline D & 131 & 78 & 59.5 & & 132 & 104 & 78.8 & & 131 & 78 & 59.5 & \\
\hline Dukes' stage & & & & 0.066 & & & & 0.116 & & & & $0.016^{*}$ \\
\hline$A$ and $B$ & 295 & 154 & 52.2 & & 279 & 226 & 81.0 & & 289 & 195 & 67.5 & \\
\hline C and D & 286 & 171 & 59.8 & & 269 & 203 & 75.5 & & 269 & 155 & 57.6 & \\
\hline Differentiation (WHO grade) & & & & 0.116 & & & & 0.326 & & & & $<0.001^{*}$ \\
\hline 1 & 19 & 9 & 47.4 & & 19 & 14 & 73.7 & & 18 & 12 & 66.7 & \\
\hline 2 & 382 & 211 & 55.2 & & 368 & 290 & 78.8 & & 374 & 254 & 67.9 & \\
\hline 3 & 155 & 86 & 55.5 & & 138 & 111 & 80.4 & & 142 & 77 & 54.2 & \\
\hline 4 & 24 & 19 & 79.2 & & 22 & 14 & 63.6 & & 23 & 7 & 30.4 & \\
\hline missing & 1 & & & & 1 & & & & 1 & & & \\
\hline Histologic type & & & & 0.680 & & & & 0.085 & & & & 0.053 \\
\hline Adenocarcinoma & 512 & 288 & 56.3 & & 481 & 382 & 79.4 & & 489 & 314 & 64.2 & \\
\hline Mucinous carcinoma & 69 & 37 & 53.6 & & 67 & 47 & 70.1 & & 69 & 36 & 52.2 & \\
\hline Tumour location & & & & 0.202 & & & & 0.073 & & & & 0.419 \\
\hline Colon & 315 & 169 & 53.7 & & 305 & 247 & 81.0 & & 311 & 191 & 61.4 & \\
\hline Rectum & 263 & 155 & 58.9 & & 240 & 179 & 74.6 & & 244 & 158 & 64.8 & \\
\hline missing & 3 & & & & 3 & & & & 3 & & & \\
\hline
\end{tabular}

* $=$-value significant. 
series of blocks were constructed, all including one sample from each patient. From each block, 4- $\mu \mathrm{m}$ slides were cut and processed for immunohistochemistry.

\section{Immunohistochemistry of MMP-2, MMP-8, and MMP-9}

The Lab Vision Autostainer TM 480 (LabVision, Fremont, CA, USA) served for immunohistochemistry. Specimens were deparaffinized in xylene and rehydrated through graded alcohol series. To retrieve antigen, samples were heated in the pretreatment module of the autostainer in Tris- $\mathrm{HCl} \mathrm{pH} 8.5$ buffer for 20 minutes at $98^{\circ} \mathrm{C}$. The samples were incubated for $5 \mathrm{~min}$ in DAKO REAL PeroxidaseBlocking Solution (DAKO, Glostrup, Denmark) for inactivation of endogenous peroxidases. The sections were incubated for one hour with a monoclonal primary MMP-2 antibody MS-806-PO (NeoMarkers) diluted 1:700, with a polyclonal MMP-8 antibody 1:100 [20] or with a polyclonal MMP-9 antibody RB-1539-R7 (NeoMarkers) 1:1500 and reacted for 30 min with the Dako REAL EnVision ${ }^{\text {th }} /$ HRP detection system, Rabbit/Mouse (ENV) reagent. Between each pair of steps the sections were rinsed with Tween-20/ PBS. The peroxidase staining was visualized with 3-amino9-ethylcarbatzole (Sigma-Aldrich, Inc., St. Louis, MO, USA). Slides were counterstained with Meyer's haematoxylin, washed in tap water for $10 \mathrm{~min}$, and mounted in aqueous mounting medium (Aquamount, BDH, Poole, UK). Stainings of specimens without primary MMP-antibody were used as negative controls. Gingival tissue was used as positive control in MMP-8 stainings, and gastric tissue in MMP-2 and MMP-9 stainings.

\section{Scoring of immunostainings}

MMP-2, MMP-8, and MMP-9 immunostainings were scored by two independent investigators (S.K. and J.H.) without knowledge of clinical outcome. In case of different scores, the consensus score was determined. The interobserver variation was low, below $5 \%$. The intensity of cytoplasmic staining in cancer cells was evaluated: strong intensity, scored as 3 , moderate as 2 , and weak as 1 . Absence of positivity in all spots was scored as 0 (Figure 1). Spots without cancer cells were excluded. For further analysis, the patients were divided into two groups, negative (0) versus positive (score $1-3$ ).

\section{Statistical analysis}

Correlations between stainings and clinicopathological variables were assessed with the $\chi^{2}$ test or Fisher's exact test when applicable. The Mann-Whitney U-test was applied to determine the correlation between age and the immunoreactivity. Life-tables were calculated with the Kaplan-Meier method. The significance of the difference between groups was assessed with the log-rank test or log-rank test for trend. Patients alive at the end of the follow-up (March 2011) and patients who died from unrelated causes or postoperatively (within 30 days from surgery) were censored. The Cox proportional hazards model served for multivariate survival analysis. Clinical variables included in the model as covariates were age, Dukes' stage, differentiation (WHO grade), tumour location (colon or rectum), and tumour histology (adenocarcinoma or mucinous carcinoma).

The likelihood ratio test was applied for exclusion or inclusion of significant variables. A p-value of 0.05 was considered significant. Statistical analyses were performed with SPSS 17.0 software.

\section{Results}

Tissue expression of MMP-2, MMP-8, and MMP-9 Immunostaining for MMP-2

Of 581 cases, MMP-2 immunoreactivity was observed in 325 (55.9\%). In 56 patients (9.6\%), MMP-2 immunopositivity was scored as strong, in $98(16.9 \%)$ as moderate, and in $171(29.4 \%)$ as weak, whereas 256 (44.1\%) lacked any MMP-2 immunopositivity. MMP-2 positivity did not correlate with clinicopathological variables (Table 1).

\section{Immunostaining for MMP-8}

Of 548 cases, MMP- 8 immunoreactivity was noticed in 429 (78.3\%). In 39 patients (7.1\%), MMP-8 immunopositivity was scored as strong, in $153(27.9 \%)$ as moderate, and in 237 (43.2\%) as weak, whereas 119 (21.7\%) lacked any MMP-8 immunopositivity. MMP-8 positivity showed no correlation with clinicopathological variables (Table 1).

\section{Immunostaining for MMP-9}

Of the 581 cases, MMP-9 immunoreactivity was observed in 350 (60.2\%). In 50 patients (8.6\%), MMP-9 immunopositivity
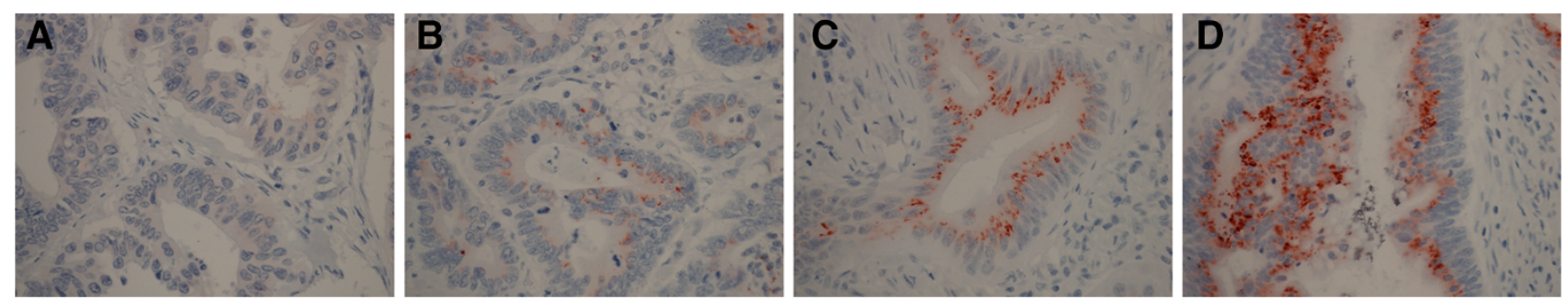

Figure 1 Immunohistochemical scoring pattern of MMP-9 in colorectal cancer. A no expression, B mild, C moderate, D strong. 
was scored as strong, in 108 (18.6\%) as moderate, and in 192 (33.0\%) as weak, whereas 208 (35.8\%) lacked any MMP-9 immunopositivity. MMP-9 correlated with WHO grade $(\mathrm{p}<0.001)$; it was more often positive in high to moderately differentiated tumours. MMP-9 immunopositivity did not correlate with Dukes' stage, but was more often positive in local (Dukes' A-B) tumours than in advanced disease $(\mathrm{p}=0.016)$ (Table 1).

In the validation series of 213 cases MMP-9 was positive in $167(78.4 \%)$. In positive patients, in $12(7.2 \%)$, the immunopositivity was scored as strong, in $41(24.6 \%)$ as moderate, and in 114 (68.3\%) as weak. No correlation appeared between clinicopathological variables and MMP-9 immunoexpression.

\section{Prognostic roles of MMP-2, MMP-8, and MMP-9}

In univariate analysis, 5-year survival was $62.5 \%$ in MMP-9-positive, and $52.2 \%$ in MMP-9-negative patients, a difference that was significant $(p=0.015)$. Advanced Dukes' stage $(\mathrm{p}<0.001)$, old age $(\mathrm{p}=0.005)$,

Table 2 Univariate analysis of correlations between preoperative characteristics and survival with Kaplan-Meier lifetable and logrank test analyses

\begin{tabular}{|c|c|c|c|c|c|}
\hline \multirow{2}{*}{$\begin{array}{l}\text { Clinicopathological } \\
\text { variable }\end{array}$} & \multicolumn{2}{|c|}{ Patients } & \multirow{2}{*}{$\frac{\text { Cumulative 5-year }}{\text { survival } \%}$} & \multirow{2}{*}{$\frac{\mathrm{X}^{2}}{\text { statistic }}$} & \multirow[t]{2}{*}{$p$-value } \\
\hline & (n) & $\%$ & & & \\
\hline MMP2 immunoreactivity & 581 & & & 0.507 & 0.477 \\
\hline Negative & 256 & 44.1 & 58.8 & & \\
\hline Positive & 325 & 55.9 & 56.0 & & \\
\hline MMP8 immunoreactivity & 548 & & & 0.129 & 0.719 \\
\hline Negative & 119 & 21.7 & 56.6 & & \\
\hline Positive & 429 & 78.3 & 58.8 & & \\
\hline MMP9 immunoreactivity & 558 & & & 5.923 & $0.015^{*}$ \\
\hline Negative & 208 & 44.9 & 52.2 & & \\
\hline Positive & 350 & 55.1 & 62.5 & & \\
\hline Gender & 619 & & & 0.000 & 0.992 \\
\hline Female & 289 & 46.7 & 56.1 & & \\
\hline Male & 330 & 53.7 & 57.5 & & \\
\hline Age & 619 & & & 7.777 & $0.005^{*}$ \\
\hline$<65$ years & 259 & 41.8 & 61.6 & & \\
\hline$\geq 65$ years & 360 & 58.2 & 53.4 & & \\
\hline Dukes' stage & 619 & & & 293.83 & $<0.001^{*}$ \\
\hline A & 91 & 14.7 & 90.3 & & \\
\hline B & 222 & 35.9 & 77.7 & & \\
\hline C & 161 & 26.0 & 51.1 & & \\
\hline $\mathrm{D}$ & 145 & 23.4 & 8.7 & & \\
\hline Differentiation (WHO grade) & 618 & & & 18.982 & $<0.001^{*}$ \\
\hline 1 & 19 & 3.1 & 83.1 & & \\
\hline 2 & 406 & 65.7 & 60.9 & & \\
\hline 3 & 165 & 26.7 & 46.3 & & \\
\hline 4 & 28 & 4.5 & 41.3 & & \\
\hline Histologic type & 619 & & & 1.311 & 0.252 \\
\hline adenocarcinoma & 539 & 87.1 & 58.1 & & \\
\hline mucinous carcinoma & 80 & 12.9 & 48.6 & & \\
\hline Tumour location & 616 & & & 2.126 & 0.145 \\
\hline Colon & 339 & 55.0 & 58.3 & & \\
\hline Rectum & 277 & 45.0 & 55.4 & & \\
\hline missing & 3 & & & & \\
\hline
\end{tabular}

${ }^{*}=\mathrm{p}$-value significant. 
and higher WHO grade $(\mathrm{p}<0.001)$ associated with poor prognosis (Table 2). The association between elevated MMP-9 immunoexpression and improved prognosis was evident only in Dukes' B tumours, but it was such a strong prognostic factor that the association was significant in analysis of the whole cohort $(\mathrm{p}=0.018)$. In Dukes' A stage 5 -year survival was $92.3 \%$ in MMP-9 positive and $87.1 \%$ in MMP-9 negative patients $(\mathrm{p}=0.417)$, in Dukes' $\mathrm{C}$ patients $56.6 \%$ versus $50.3 \%(\mathrm{p}=0.618)$, and in Dukes' D patients $6.8 \%$ versus $9.6 \%(\mathrm{p}=0.992)$.

In Cox stepwise multivariate analysis, age $(\mathrm{p}<0.001)$, Dukes' stage $(\mathrm{p}<0.001)$, location $(\mathrm{p}=0.016)$, and differentiation $(\mathrm{p}=0.005)$ were all independent prognostic factors (Table 3). In Dukes' B tumours, MMP-9 positivity was an independent prognostic factor $(\mathrm{p}=0.034)$, as was tumour location $(\mathrm{p}=0.041)$.

In the validation series, 5 -year survival was $64.8 \%$ in MMP-9 positive patients compared to $63.5 \%$ in those MMP-9 negative, $(\mathrm{p}=0.418)$. In subgroup analysis of Dukes' stages there were no significant differences in survival according to stage.

Neither MMP-2 immunoexpression $(\mathrm{p}=0.477)$ nor MMP-8 immunoexpression $(\mathrm{p}=0.719)$ associated in univariate analysis with prognosis.

\section{Discussion}

It is clinically relevant to identify a prognostic marker in Dukes' B (stage II) disease. This stage is classified as local disease, but $20 \%$ will still die from this, with surgery curing $80 \%$. We urgently need biomarkers to identify those $20 \%$ at risk in order to offer them adjuvant treatment. Here we show that MMP-9 tumour expression is an independent prognostic factor in Dukes' B colorectal cancer. In the other stage groups, no significant difference in survival emerged. In Dukes' B, the difference was so great, that it affected analysis of the whole cohort. In Dukes' B and $\mathrm{C}$ of the validation series, we noticed poorer prognosis among patients with MMP-9 negative tumours, but the differences were not significant.

The overall survival was better in the validation series. The difference in survival may have several reasons. First, pathologic routines have changed and more lymph nodes are nowadays evaluated, which may lead to stage migration. Second, the surgical technique has changed, especially in rectal cancer treatment. Third, the more frequent use of adjuvant treatment might have improved survival.

Our results differ from those in a recent study of stage II CRC in which high MMP-9 expression associated with higher recurrence rate, shorter disease-free survival, and also shorter disease-specific survival, but association with disease-specific survival was not significant in multivariate analysis [21]. In CRC patients, high MMP-9 expression has been associated with liver metastasis [22]. We also analyzed high versus low immunoexpression, but found no association with survival (data not shown). Elevated MMP-9 mRNA levels have been associated with poor disease-free and overall survival [14]. On the other hand, some studies using immunohistochemistry have failed to show any correlation between MMP-9 and survival or clinicopathological parameters [16,23]. In other cancer forms, such as lung cancer, head and neck squamous cell carcinoma, and gastric cancer, MMP-9 associates with poor prognosis [24-26]. Interestingly, in early breast cancer, elevated MMP-9 associates with better prognosis [27].

In cancer, the host response, like the intra- or peritumoral inflammation reaction or desmoplasia, can predict

Table 3 Cox stepwise multivariate regression analysis of prognostic factors in $\mathbf{5 5 8}$ colorectal cancer patients (MMP-9)

\begin{tabular}{|c|c|c|c|c|}
\hline Covariate & Wald statistic & p-value & RH & $95 \% \mathrm{Cl}$ \\
\hline Age & 31.209 & $<0.001$ & 1.031 & $1.020-1.043$ \\
\hline Dukes' stage & 299.615 & $<0.001$ & & \\
\hline \multicolumn{5}{|l|}{ A } \\
\hline B & 2.397 & & 1.664 & $0.874-3.166$ \\
\hline C & 27.913 & & 5.274 & $2.846-9.773$ \\
\hline D & 117.503 & & 30.446 & $16.417-56.464$ \\
\hline Differentiation (WHO Grade) & 12.502 & 0.005 & & \\
\hline \multicolumn{5}{|l|}{1} \\
\hline 2 & 2.246 & & 2.143 & $0.791-5.806$ \\
\hline 3 & 4.577 & & 3.031 & $1.097-8.373$ \\
\hline 4 & 6.353 & & 4.293 & $1.383-13.330$ \\
\hline Tumour location in rectum & 5.815 & 0.016 & 1.373 & $1.061-1.776$ \\
\hline Histologic type & & NS & & \\
\hline MMP9 & & NS & & \\
\hline
\end{tabular}

$\mathrm{NS}=$ not significant, $\mathrm{RH}=$ relative hazard, $\mathrm{Cl}=$ confidence interval at $95 \%$ level. 
better prognosis [6-8]. Theoretically, some matrixdegrading proteinases may play a defensive role by supporting the immune/inflammatory response. Stromal expression of MMP-9 inversely associates with liver metastasis and tumour infiltration in CRC [28]. Stromal MMP-9 positivity also inhibits metachronous haematogenic metastasis in Dukes' B and C colorectal cancer patients [29]. Here, we did not evaluate stromal MMP-9 expression, because we used tissue arrays with punches taken from cancerous regions, and our samples were unsuitable for reliable stroma evaluation. The TMA is not as reliable as analysis of whole tissue sections because of intra-tumoural heterogenity of immunohistochemical expression. However, the results of evaluation of TMAs and those of whole tissue sections have been shown to be in concordance [30].

Tumour expression of MMP-2 has been associated with poor prognosis in colorectal [11-13,31], gastric [25], ovarian [32], and breast cancer [33]. Here, we found no correlation between MMP-2 immunoexpression and clinicopathological variables or prognosis of CRC. Results similar to ours have emerged in CRC [34]. Thereby the role of MMP-2 in CRC is still controversial.

In breast cancer, MMP- 8 changes metastatic potential in vitro [15], and in melanoma and lung cancer it inhibits metastasis formation by modulating cancer cell invasion and adhesion [14]. It was expected that MMP-8 might be a marker for improved prognosis in colorectal cancer, but we noticed no association between MMP-8 immunoexpression and survival.

\section{Conclusion}

The role of MMP-9 immunoexpression in colorectal cancer is dual; it plays a role in matrix degradation enabling tumour invasion, but it also seems to act as a supportive factor for hosts' defensive mechanisms against cancer spread. Here we show that immunoexpression of MMP-9 is a promising prognostic marker in Dukes' B (Stage II) CRC, the group of patients for whom we need new markers to identify those at risk who need adjuvant treatment.

\section{Ethics approval}

The study has been approved by the Surgical Ethics Committee of Helsinki University Central Hospital (Dnro HUS 226/E6/06) and National Supervisory Authority for Welfare and Health.

\section{Abbreviations}

BM: Basement membrane; CRC: Colorectal cancer; EMC: Extracellular matrix; H\&E: Haematoxylin-eosin; MMP: Matrix metalloproteinase; mRNA: Messenger ribonuclein acid; TMA: Tissue microarray.

\section{Competing interests}

The authors declare that they have no competing interests.

\section{Authors' contribution}

SK participated in patient data collection, scored samples and, wrote the manuscript. JH scored samples with SK and participated in drafting the manuscript. NL participated in sample analysis. ML participated in statistical analysis. TS provided the MMP-8 antibody and participated in planning and evaluating MMP-8 stainings. JL participated in patient data collection and drafting the manuscript, and performed the statistical analysis. $\mathrm{CH}$ conceived the study, participated in its design and co-ordination, was responsible for immunohistochemical stainings and participated in drafting the manuscript. All authors read and approved the final manuscript.

\section{Acknowledgements}

We thank Päivi Peltokangas, Tuire Koski, and Elina Aspiala for excellent technical assistance.

\section{Funding}

This study was supported by Finska Läkaresällskapet, Medicinska Understödsföreningen Liv och Hälsa, Stiftelsen Dorothea Olivia, Karl Walter och Jarl Walter Perkléns minne, the Sigrid Jusélius Foundation, and a special governmental subsidy for research and training.

\section{Author details}

'Department of Surgery, Helsinki University Central Hospital, P.O. Box 440, 00029 HUS, Helsinki, Finland. ${ }^{2}$ Department of Pathology, Haartman Institute, University of Helsinki, Helsinki FIN-00014 HY, Finland. ${ }^{3}$ Institute for Molecular Medicine Finland (FIMM), University of Helsinki, Helsinki FIN-00014 HY,

Finland. ${ }^{4}$ Institute of Dentistry, University of Helsinki and Department of Oral and Maxillofacial Diseases, Helsinki University Central Hospital, Helsinki, Finland

Received: 7 June 2012 Accepted: 29 November 2012

Published: 7 December 2012

\section{References}

1. Jemal A, Bray F, Center MM, Ferlay J, Ward E, Forman D: Global cancer statistics. CA Cancer J Clin 2011, 61(2):69-90.

2. Compton CC: Pathology report in colon cancer: what is prognostically important? Dig Dis 1999, 17(2):67-79.

3. Compton CC, Fielding LP, Burgart L, Conley B, Cooper HS, Hamilton SR, Hammond ME, Henson DE, Hutter RV, Nagle RB, Nielsen ML, Sargent DJ, Taylor CR, Welton M, Willett C: Prognostic factors in colorectal cancer. College of American Pathologists Consensus Statement 1999. Arch Pathol Lab Med 2000, 124(7):979-994.

4. Yang Z, Wang L, Kang L, Xiang J, Peng J, Cui J, Huang Y, Wang J: Clinicopathologic characteristics and outcomes of patients with obstructive colorectal cancer. J Gastrointest Surg 2011, 15(7):1213-1222.

5. Anwar MA, D'Souza F, Coulter R, Memon B, Khan IM, Memon MA: Outcome of acutely perforated colorectal cancers: experience of a single district general hospital. Surg Oncol 2006, 15(2):91-96.

6. Crispino P, De Toma G, Ciardi A, Bella A, Rivera M, Cavallaro G, Polistena A, Fornari F, Unim H, Pica R, Cassieri C, Mingazzini PL, Paoluzi P: Role of desmoplasia in recurrence of stage II colorectal cancer within five years after surgery and therapeutic implication. Cancer Invest 2008, 26(4):419-425

7. Galon J, Costes A, Sanchez-Cabo F, Kirilovsky A, Mlecnik B, Lagorce-Pages C, Tosolini M, Camus M, Berger A, Wind P, Zinzindohoue F, Bruneval P, Cugnenc PH, Trajanoski Z, Fridman WH, Pages F: Type, density, and location of immune cells within human colorectal tumors predict clinical outcome. Science 2006, 313(5795):1960-1964.

8. Ropponen KM, Eskelinen MJ, Lipponen PK, Alhava E, Kosma VM: Prognostic value of tumour-infiltrating lymphocytes (TILs) in colorectal cancer. J Pathol 1997, 182(3):318-324.

9. Coussens LM, Werb Z: Matrix metalloproteinases and the development of cancer. Chem Biol 1996, 3(11):895-904.

10. Hasty KA, Jeffrey JJ, Hibbs MS, Welgus HG: The collagen substrate specificity of human neutrophil collagenase. J Biol Chem 1987, 262 (21):10048-10052.

11. Matsuyama Y, Takao S, Aikou T: Comparison of matrix metalloproteinase expression between primary tumors with or without liver metastasis in pancreatic and colorectal carcinomas. J Surg Oncol 2002, 80(2):105-110. 
12. Papadopoulou S, Scorilas A, Arnogianaki N, Papapanayiotou B, Tzimogiani A, Agnantis N, Talieri M: Expression of gelatinase-A (MMP-2) in human colon cancer and normal colon mucosa. Tumour Biol 2001, 22(6):383-389.

13. Hilska M, Roberts PJ, Collan YU, Laine VJ, Kossi J, Hirsimaki P, Rahkonen O, Laato M: Prognostic significance of matrix metalloproteinases-1, $-2,-7$ and -13 and tissue inhibitors of metalloproteinases-1, $-2,-3$ and -4 in colorectal cancer. Int J Cancer 2007, 121(4):714-723.

14. Zeng ZS, Huang Y, Cohen AM, Guillem JG: Prediction of colorectal cancer relapse and survival via tissue RNA levels of matrix metalloproteinase-9. J Clin Oncol 1996, 14(12):3133-3140.

15. Karakiulakis G, Papanikolaou C, Jankovic SM, Aletras A, Papakonstantinou E, Vretou E, Mirtsou-Fidani V: Increased type IV collagen-degrading activity in metastases originating from primary tumors of the human colon. Invasion Metastasis 1997, 17(3):158-168.

16. Roca F, Mauro LV, Morandi A, Bonadeo F, Vaccaro C, Quintana GO, Specterman S, de Kier Joffe EB, Pallotta MG, Puricelli LI, Lastiri J: Prognostic value of E-cadherin, beta-catenin, MMPs (7 and 9), and TIMPs (1 and 2) in patients with colorectal carcinoma. J Surg Oncol 2006, 93(2):151-160.

17. Gutierrez-Fernandez A, Fueyo A, Folgueras AR, Garabaya C, Pennington CJ, Pilgrim S, Edwards DR, Holliday DL, Jones JL, Span PN, Sweep FC, Puente XS, Lopez-Otin C: Matrix metalloproteinase-8 functions as a metastasis suppressor through modulation of tumor cell adhesion and invasion. Cancer Res 2008, 68(8):2755-2763.

18. Montel V, Kleeman J, Agarwal D, Spinella D, Kawai K, Tarin D: Altered metastatic behavior of human breast cancer cells after experimental manipulation of matrix metalloproteinase 8 gene expression. Cancer Res 2004, 64(5):1687-1694

19. Davis NC, Evans EB, Cohen JR, Theile DE: Staging of colorectal cancer. The Australian clinico-pathological staging (ACPS) system compared with Dukes' system. Dis Colon Rectum 1984, 27(11):707-713.

20. Sorsa T, Ding Y, Salo T, Lauhio A, Teronen O, Ingman T, Ohtani H, Andoh N, Takeha S, Konttinen YT: Effects of tetracyclines on neutrophil, gingival and salivary collagenase. A functional and western-blot assessment with special reference to their cellular sources in periodontal disease. Ann N Y Acad Sci 1994, 732:112-131.

21. Buhmeida A, Bendardaf R, Hilska M, Collan $Y$, Laato $M$, Syrjanen S, Syrjanen $K$, Pyrhonen S: Prognostic significance of matrix metalloproteinase- 9 (MMP-9) in stage II colorectal carcinoma. J Gastrointest Cancer 2009, 40(3-4):91-97.

22. Koumura H, Sugiyama $Y$, Kunieda K, Saji S: Significance in gene expression of matrix metalloproteinase-9, urokinase-type plasminogen activator and tissue inhibitor of metalloproteinase for metastases of gastric and/or colo-rectal cancer. Gan To Kagaku Ryoho 1997, 24(Suppl 2):324-331.

23. Jensen SA, Vainer B, Bartels A, Brunner N, Sorensen JB: Expression of matrix metalloproteinase 9 (MMP-9) and tissue inhibitor of metalloproteinases 1 (TIMP-1) by colorectal cancer cells and adjacent stroma cellsassociations with histopathology and patients outcome. Eur J Cancer 2010, 46(18):3233-3242.

24. Brown PD, Bloxidge RE, Stuart NS, Gatter KC, Carmichael J: Association between expression of activated 72-kilodalton gelatinase and tumor spread in non-small-cell lung carcinoma. J Nat/ Cancer Inst 1993 85(7):574-578

25. Ruokolainen H, Paakko P, Turpeenniemi-Hujanen T: Expression of matrix metalloproteinase-9 in head and neck squamous cell carcinoma: a potential marker for prognosis. Clin Cancer Res 2004, 10(9):3110-3116.

26. Sier CF, Kubben FJ, Ganesh S, Heerding MM, Griffioen G, Hanemaaijer R, van Krieken JH, Lamers CB, Verspaget HW: Tissue levels of matrix metalloproteinases MMP-2 and MMP-9 are related to the overall survival of patients with gastric carcinoma. Br J Cancer 1996, 74(3):413-417.

27. Scorilas A, Karameris A, Arnogiannaki N, Ardavanis A, Bassilopoulos P, Trangas T, Talieri M: Overexpression of matrix-metalloproteinase- 9 in human breast cancer: a potential favourable indicator in node-negative patients. Br J Cancer 2001, 84(11):1488-1496

28. Takeha S, Fujiyama Y, Bamba T, Sorsa T, Nagura H, Ohtani H: Stromal expression of MMP-9 and urokinase receptor is inversely associated with liver metastasis and with infiltrating growth in human colorectal cancer: a novel approach from immune/inflammatory aspect. Jpn J Cancer Res 1997, 88(1):72-81.
29. Saito K, Takeha S, Shiba K, Matsuno S, Sorsa T, Nagura H, Ohtani H: Clinicopathologic significance of urokinase receptor- and MMP-9positive stromal cells in human colorectal cancer: functional multiplicity of matrix degradation on hematogenous metastasis. Int J Cancer 2000, 86(1):24-29

30. Kallioniemi OP, Wagner U, Kononen J, Sauter G: Tissue microarray technology for high-throughput molecular profiling of cancer. Hum Mol Genet 2001, 10:657-662.

31. Masuda $\mathrm{H}$, Aoki H: Host expression of matrix metalloproteinase-2 and tissue inhibitor of metalloproteinase- 2 in normal colon tissue affects metastatic potential of colorectal cancer. Dis Colon Rectum 1999, 42(3):393-397

32. Westerlund A, Apaja-Sarkkinen M, Hoyhtya M, Puistola U, TurpeenniemiHujanen T: Gelatinase A-immunoreactive protein in ovarian lesionsprognostic value in epithelial ovarian cancer. Gynecol Oncol 1999, 75(1):91-98

33. Talvensaari-Mattila A, Paakko P, Turpeenniemi-Hujanen T: Matrix metalloproteinase-2 (MMP-2) is associated with survival in breast carcinoma. Br J Cancer 2003, 89(7):1270-1275.

34. Unsal D, Akyurek N, Uner A, Erpolat OP, Han U, Akmansu M, Mentes BB, Dursun A: Gelatinase B expression as a prognostic factor in patients with stage II/III rectal carcinoma treated by postoperative adjuvant therapy. Am J Clin Oncol 2008, 31(1):55-63.

doi:10.1186/1472-6890-12-24

Cite this article as: Koskensalo et al.: Lack of MMP-9 expression is a marker for poor prognosis in Dukes' B colorectal cancer. BMC Clinical Pathology 2012 12:24

\section{Submit your next manuscript to BioMed Central and take full advantage of:}

- Convenient online submission

- Thorough peer review

- No space constraints or color figure charges

- Immediate publication on acceptance

- Inclusion in PubMed, CAS, Scopus and Google Scholar

- Research which is freely available for redistribution

Submit your manuscript at www.biomedcentral.com/submit
C Biomed Central 